\title{
Simulation of the micro Single Point Incremental forming process of very thin sheets
}

\author{
Stéphanie Thuillet, Pierre-Yves Manach, Fabrice Richard and Sébastien Thibaud
}

\author{
Stéphanie Thuillet. Univ. Bretagne Sud, IRDL, UMR CNRS 6027, 56100 Lorient, France \\ Pierre-Yves Manach. Univ. Bretagne Sud, IRDL, UMR CNRS 6027, 56100 Lorient, France \\ Fabrice Richard. Univ. Bourgogne Franche-Comté, FEMTO-ST Institute, CNRS/UFC/ENSMM/UTBM, France \\ Sébastien Thibaud. Univ. Bourgogne Franche-Comté, FEMTO-ST Institute, CNRS/UFC/ENSMM/UTBM, France \\ Corresponding author: stephanie.thuillet@univ-ubs.fr
}

\begin{abstract}
The purpose of this paper is to simulate a complex forming process with parameters identified from tensile and shear tests. An elastic-plastic model is retained which combines a Hill's 1948 anisotropic criterion and plastic potential using a non-associated flow rule. Firstly, a mechanical characterization is made with homogenous tests like tensile and shear tests [1]. On the other hand a process of micro Single Point Incremental forming is simulated [2]. It consists in deforming a clamped blank using a hemispherical punch which has a small diameter compared to the blank dimensions. From a small-size sheet of $0.2 \mathrm{~mm}$ thick, a square-based pyramid is obtained incrementally, with a define height path and advanced speed, by a tool instrumented to measure the forming force, which deforms locally the material. It is shown that the non-associated flow plasticity model leads to a good agreement between experimental and numerical results for the evolution of the punch force during the process.
\end{abstract}

Keywords. Experimental Characterization, Micro Single Point Incremental Forming, Very Thin Sheet, Numerical Simulation

\section{Introduction}

The miniaturization of device is a race which started three decades ago, and this tendency led to a high demand for components with sub-millimeter dimensions. In order to meet the needs of industries with increasing production rates, the forming processes by plastic deformation remains the most common technological solution for the manufacture of miniature parts, such as those found in the watchmaker industry. Since the beginning of mechanical watchmaking, copper alloys have been part of the standard materials of various watchmaking components. In fact, these parts require peculiar mechanical properties, both machinability and in service life, by meeting more and more requirements. In this context, the use of the incremental sheet forming is interesting for the small batch production and rapid prototyping [1]. Powell and Andrew [2] developed for the first time incremental forming process. Several studies have been carried out to investigate the influence of process parameters on surface quality [3], geometric accuracy [4], forming forces [5], thinning and sustainability. Regarding thin metallic sheet, the identification of the constitutive law is often performed by using mechanical tests, i.e. tensile, bending, and shear tests [6]. However, deformations' modes encountered during micro Single Incremental forming ( $\mu$ SPIF) process are essentially those of plane tension. Associated plasticity models are often not competent enough because they do not offer sufficient flexibility to describe well both the anisotropy of hardening and plastic flow. In order to obtain a more precise model while keeping simple laws, it is possible to use a non-associated plastic flow, that is to say to use a function to describe the plastic potential and an other for the load surface in order to be able to separately control the deformation anisotropy and the material flow stress [7]. In this work, an anisotropic macroscopic approach is used to model the material behavior. Concerning anisotropy, the yield criteria frequently used can be those of Barlat 2003 [8] or that of Hill48 [9]. Hill48 has the advantage to use a quadratic function with anisotropic coefficients which describe the values of the Lankford ratios and the flow stress for different orientations relative to the rolling direction. The objective of this study is to simulate a micro Single Incremental forming process with parameters identified from tensile and shear tests. 


\section{Classical characterization}

\subsection{Material and mechanical tests}

The material is a $0.2 \mathrm{~mm}$ thick copper-beryllium alloy sheet, which principal properties are in Table 1 . In order to determine the behavior under different stress states, an experimental characterization was carried out using uniaxial tensile tests for different orientations $\left(0^{\circ}, 45^{\circ}, 90^{\circ}\right)$ to the rolling direction (RD).

The Cauchy stress $\sigma$ is calculated by using the applied force:

$$
\sigma_{n}=\frac{F}{S_{0}} \quad \sigma=\sigma_{n}\left(1+\varepsilon_{n}\right)
$$

Where $F, S_{0}$ and $\varepsilon_{n}$ are respectively the tensile force, the initial area of the specimen section and the longitudinal deformation.

The transverse deformation is measured by image correlation and the normal deformation is calculated from the assumption of invariance of the plastic volume $\operatorname{tr}\left(\varepsilon^{\mathrm{p}}\right)=0$ and the longitudinal deformation.

$$
\varepsilon_{n}=\frac{\Delta L}{L_{0}} \quad \varepsilon=\ln \left(1+\varepsilon_{n}\right)
$$

$L_{0}$ is the initial length and $\Delta L$ the length traction during tensile test.

The Lankford ratios $r_{0}, r_{45}$ and $r_{90}$ are accessible thanks to the tensile test. They correspond to the slope of the transverse strain curve according to the normal strain $\varepsilon_{22}{ }^{\mathrm{p}}=f\left(\varepsilon_{33}{ }^{\mathrm{p}}\right)$.

Shear tests were carried out in order to be able to go further in strains compared to a simple tensile test.

Following formula is used to have access to the stress:

$$
\tau=\frac{F}{S}
$$

Where $F$ is the applied force and $S$ the shear section. The strain $\gamma$ corresponds to twice the shear strain.

Table 1. Material parameters of CuBe.

\begin{tabular}{ccccccc}
\hline $\mathrm{E}(\mathrm{GPa})$ & $v$ & $\sigma_{y}(\mathrm{MPa})$ & UTS $(\mathrm{MPa})$ & $r_{0}$ & $r_{45}$ & $r_{90}$ \\
\hline 131 & 0.3 & 645 & 1000 & 0.62 & 1.10 & 0.85 \\
\hline
\end{tabular}




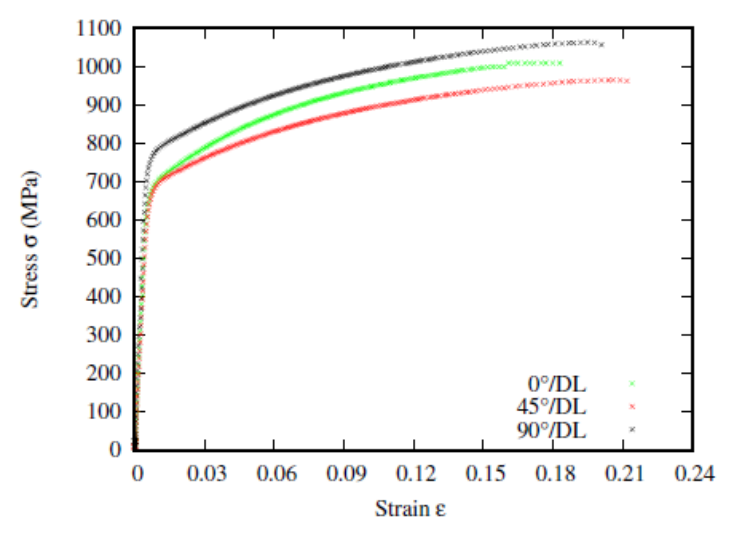

(a)

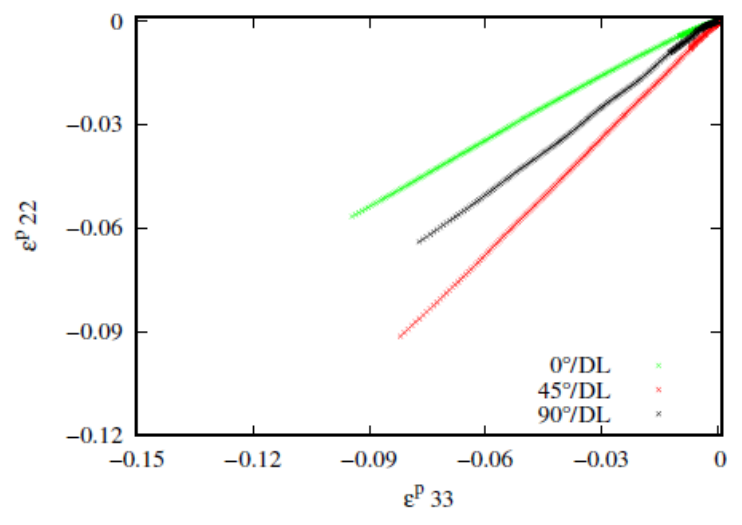

(b)

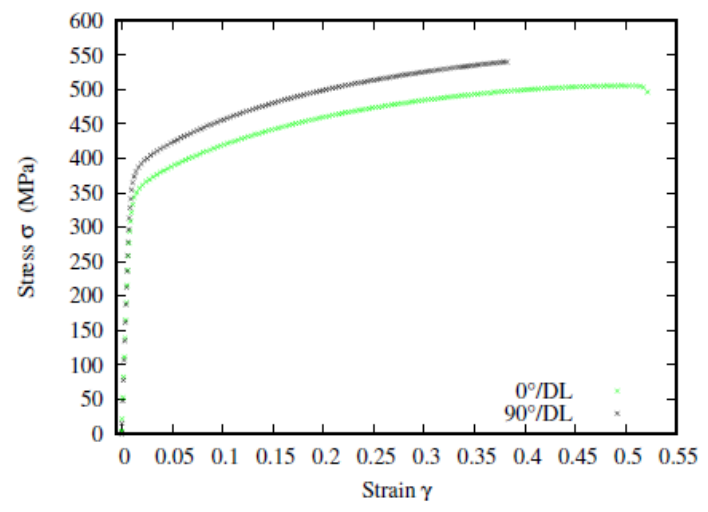

(c)

Figure 1. Work hardening curves (a), anisotropic coefficients (b) for a tensile test, work hardening during a shear test (c) for CuBe alloy of thickness $0.2 \mathrm{~mm}$

On the figure 1.a, the work hardening curves are plotted for different orientations to the rolling direction. It is observed that the mechanical properties in the transverse direction are higher both during the tensile and the shear tests, especially the yield stress is higher. The values of the anisotropy ratios also show an anisotropy in terms of strains in addition to that observed for the stresses. A different evolution of the deformation is clearly observed, it shows an anisotropy of the material behavior.

The average anisotropy coefficient $\bar{r}$ that characterizes overall normal anisotropy can also be calculated by an average of anisotropy coefficients calculated for different orientations. The more $\bar{r}$ is closed to 1 , the more the normal anisotropy is low.

$$
\bar{r}=\frac{r_{0}+2 r_{45}+r_{90}}{4}=0.92
$$

Planar anisotropy coefficients $\Delta r$ assess the variation of anisotropy in the sheet plane according to the orientation in relation to the rolling direction: 
Simulation of the micro Single Point Incremental forming process of very thin sheets

$$
\Delta r=\frac{r_{0}-2 r_{45}+r_{90}}{2}=-0.37
$$

A zero value of $\Delta r$ implies that the anisotropic deformation is the same regardless of the orientation, i.e. the material is isotropic in the plane.

Results show that the CuBe alloy has a normal anisotropy enough low but a pretty significant planar anisotropy.

\section{Constitutive laws in non-associated plasticity}

In this work, the framework of thermodynamics of irreversible processes is used to define the overall constitutive equations of anisotropic elastoplastic model under isothermal conditions. The assumption of small elastic strains, which is verified for most metallic materials, is adopted, then this leads to the additive decomposition of the total strain rate tensor. All phenomena considered are represented by a pair of state variables. As showed in Table 2, the following pairs of state variables are introduced: (i) $\left(\varepsilon_{i j}{ }^{e}, \sigma_{i j}\right)$ represents the elastoplastic flow; (ii) $\left(r_{1}, R_{1}\right)$ represents the nonlinear isotropic hardening (Voce) and (iii) $\left(r_{2}, R_{2}\right)$ represents the linear isotropic hardening.

\begin{tabular}{lcc}
\hline Phenomena & State variables & Associeted variables \\
\hline Elastoplasticity & $\varepsilon_{i j}^{e}, \varepsilon_{i j}^{p}$ & $\sigma_{i j}$ \\
\hline Isotropic hardening & $r_{1}, r_{2}$ & $R_{1}, R_{2}$ \\
\hline
\end{tabular}

A model is proposed after the experimental observations, we propose the following form to express the specific free energy $\Psi$ :

Table 2. State and associated variables.

$$
\rho \Psi\left(\boldsymbol{\varepsilon}^{e}, r_{1}, r_{2}\right)=\frac{1}{2} \boldsymbol{\varepsilon}^{e}: \boldsymbol{C}_{(E, v)}: \boldsymbol{\varepsilon}^{e}+\frac{1}{2} \cdot b_{1} \cdot Q_{1} \cdot r_{1}^{2}+\frac{1}{2} K \cdot r_{2}^{2}
$$

A Hill48 criterion is retained with a non-associated plasticity (Non Associated Flow Rule). In fact, according to Safaei [10] a function based on the Hill criterion may be used in order to describe the potential separately and therefore to better describe the material behavior. Cardoso [11] also choose this criterion to develop functions capable of correctly describing the anisotropy values $r$ and the flow stress simultaneously. One function describes the yield surface $f$ (Eq.6) and the other is dedicated to the work hardening $g$ (Eq.7).

$$
\begin{aligned}
& f\left(\boldsymbol{\sigma}, R_{1}, R_{2}\right)=\sqrt{F^{\prime\left(\sigma_{22}-\sigma_{33}\right)^{2}}+G^{\prime\left(\sigma_{33}-\sigma_{11}\right)^{2}+H^{\prime\left(\sigma_{11}-\sigma_{22}\right)^{2}}+2 L^{\prime} \sigma_{12}^{2}+2 M^{\prime} \sigma_{23}^{2}+2 N^{\prime} \sigma_{31}^{2}}-\sigma_{y}-R_{1}-R_{2}=0} \\
& g\left(\sigma, R_{1}, R_{2}\right)=\sqrt{F\left(\sigma_{22}-\sigma_{33}\right)^{2}+G\left(\sigma_{33}-\sigma_{11}\right)^{2}+H\left(\sigma_{11}-\sigma_{22}\right)^{2}+2 L \sigma_{12}^{2}+2 M \sigma_{23}^{2}+2 N \sigma_{31}^{2}}-R_{1}-R_{2}+\frac{R_{1}^{2}}{2 Q_{1}}
\end{aligned}
$$


The relations between thermodynamic forces and internal variables are also expressed:

$$
\begin{aligned}
& \boldsymbol{\sigma}=\mathbf{C}_{(E, v)}:\left(\boldsymbol{\varepsilon}-\boldsymbol{\varepsilon}^{p}\right) \\
& \dot{R}_{1}=b_{1}\left(Q_{1}-R_{1}\right) \cdot \dot{\lambda} \\
& \dot{R}_{2}=K \cdot \dot{\lambda}
\end{aligned}
$$

The plastic multiplier $\lambda$ in Eq.9, Eq.10 is determined using the consistency condition $f=0$ if $f=0$.

\subsection{Identification of plastic parameters}

The model contains 8 independent parameters (E, n, F, G, N, F', G', N') with $H=1-G$ and $H^{\prime}=1-G^{\prime}$. Out-of-plane parameters (L, M, L', M') were not identified and considered as constants and equal to isotropic values $L=L^{\prime}=M$ $=M^{\prime}=1.5$. Parameters are identified thanks to a minimization algorithm (Levenberg-Marquardt) available in the MIC2M software developed by Richard [12]. Experimental tensile and shear tests are used to identified parameters. The anisotropic coefficient for the yield surface description and work hardening definition are presented in Table 3 :

Table 3. Anisotropic parameters

\begin{tabular}{lcccccc}
\hline \multirow{2}{*}{ Yield surface } & $\mathrm{F}^{\prime}$ & $\mathrm{G}^{\prime}$ & $\mathrm{H}^{\prime}$ & $\mathrm{L}$ & $\mathrm{M}^{\prime}$ & $\mathrm{N}^{\prime}$ \\
\cline { 2 - 7 } & 0.24 & 0.32 & 0.68 & 1.50 & 1.50 & 1.99 \\
\hline \hline \multirow{2}{*}{ Work hardening } & $\mathrm{F}$ & $G$ & $\mathrm{H}$ & $\mathrm{L}$ & $\mathrm{M}$ & $\mathrm{N}$ \\
\cline { 2 - 7 } & 0.42 & 0.63 & 0.37 & 1.50 & 1.50 & 1.71 \\
\hline
\end{tabular}

The set of parameters is identified using the experimental curve in the direction of rolling, the following coefficients are obtained and defined in Table 4:

Table 4. Material parameters.

\begin{tabular}{cccc}
\hline$\sigma_{y}(\mathrm{MPa})$ & $Q_{1}(\mathrm{MPa})$ & $K(\mathrm{MPa})$ & $\mathrm{b}$ \\
\hline 645 & 227 & 886 & 32.31 \\
\hline
\end{tabular}

Tensile and shear tests are simulated with the constitutive equations implemented in MIC2M and integrated by MIC2M using a Runge-Kutta algorithm. 


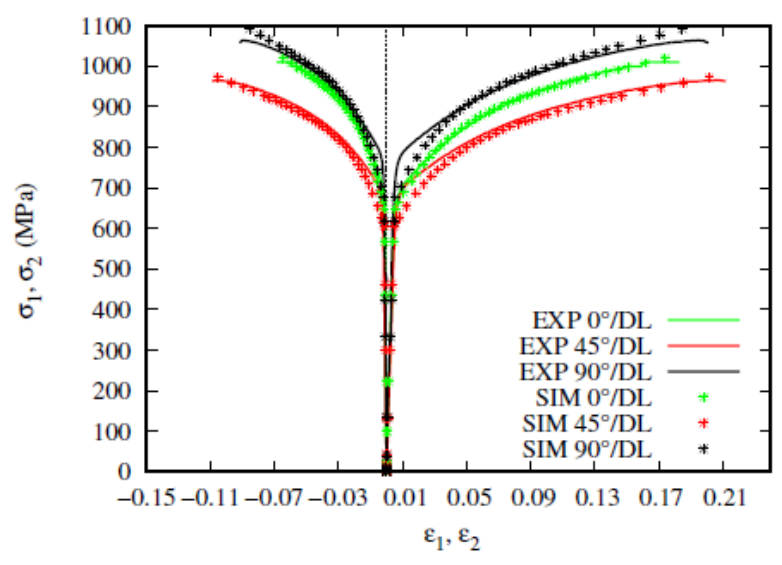

(a)

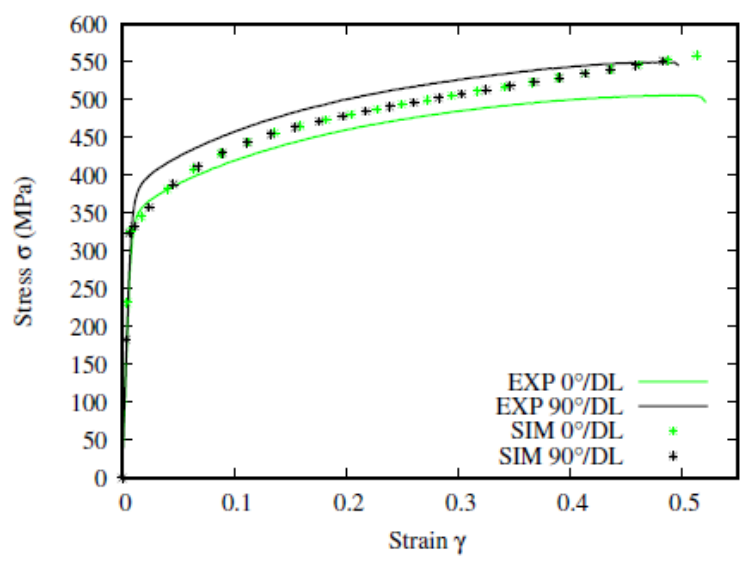

(b)

Figure 2 Comparison of experimental and numerical hardening curves with parameters identified with MIC2M for a tensile (a) and shear (b) tests for CuBe alloy of thickness $0.2 \mathrm{~mm}$

Simulations carried out with parameters identified by MIC2M are in good agreement with experimental results.

\section{Single Point Incremental Forming}

The micro Single Point Incremental Forming process ( $\mu$ SPIF) can be used to form very thin sheets [13][14]. It consists in locally deforming a clamped blank using a hemispherical punch which has a small diameter compared to the blank dimensions. The SPIF device allows to have a maximum of plastic parameters involved in only one test. The Micro incremental deformation testing device represented in Fig.3 is composed of a fixed die support, a modular die, a fixed blank holder clamped to the die using screws and a forming punch with a radius of $0.5 \mathrm{~mm}$. The lubrication of the sheet/tool interface (water/oil mixture) is used to improve the sheet formability. The tool moves with a constant feed rate of $500 \mathrm{~mm} / \mathrm{min}$ and rotates with a speed rate of $500 \mathrm{rpm}$. A 3-axis micro-milling CNC Machine (KERN HSPC) is used and the forming forces $\overrightarrow{F^{*}}$ exp are acquired by using a 4- axis dynamometer. The KERN HSPC can be repositioned in $\mu \mathrm{m}$ but its repeatability is $5 \mu \mathrm{m}$. From a $0.2 \mathrm{~mm}$ thick sheet, a square-based pyramid is obtained incrementally, with a define height pass and feed rate. 

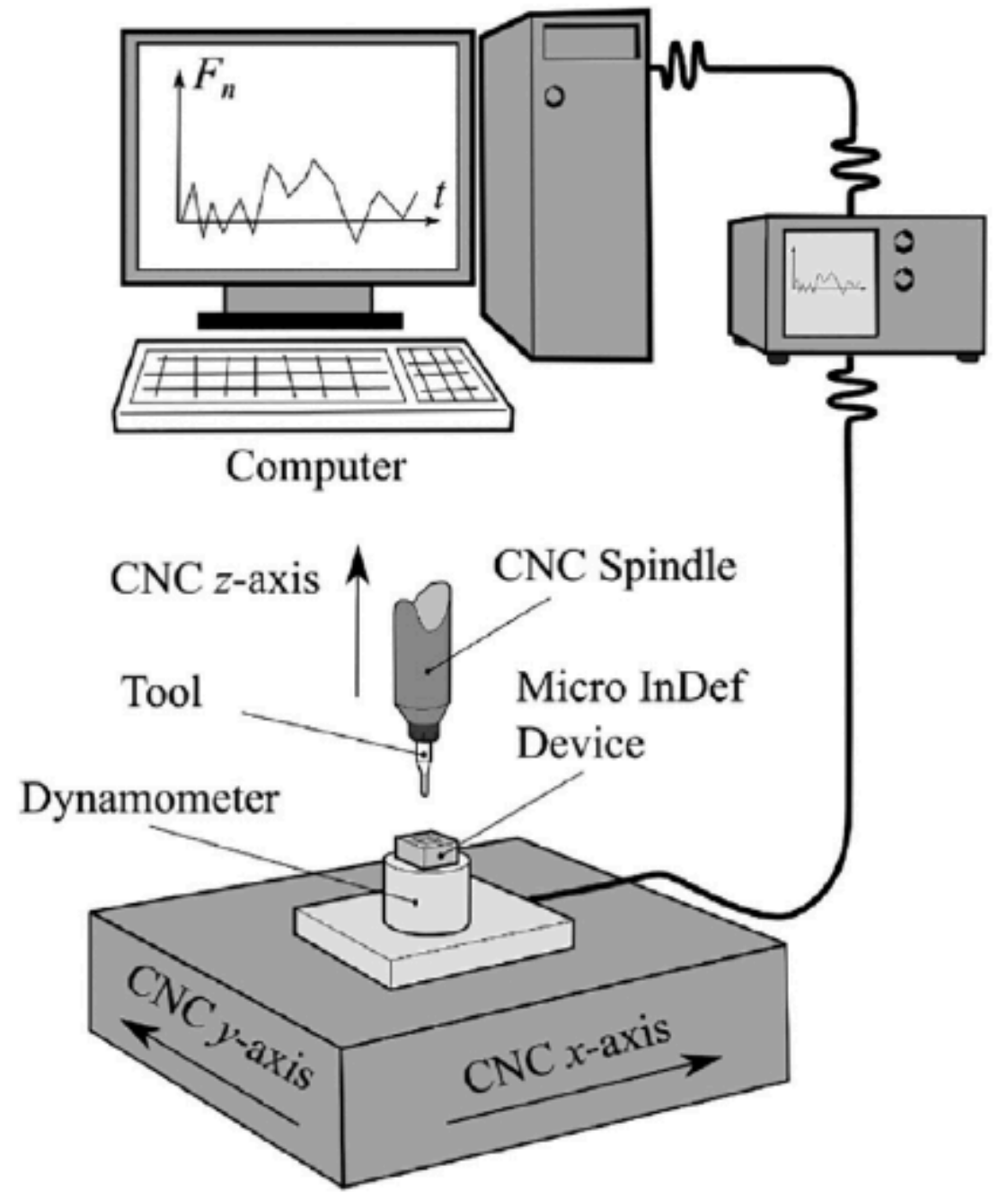

Figure 3. Principe of force acquisition for the Micro Incremental Deformation device

Two approaches are used in Fig 4: the helical paths (continuous paths) and the constant Z-level one (discontinuous path). Different parameters are tested in order to study their influence on the Z-axis force. First of all the influence of the lubrication is checked and it was observed to be weak, however lubrification is activated in order to decrease friction between the tool and the material. Then the pass height for the two approaches is tested. In the two strategies when the pass height increases the axial force in $\mathrm{Z}$ direction also increases. By comparing the two approaches it can be observed for the constant Z-level strategy the influence of Z-increment on the curve while the helical paths approach is smoother. These strategies are reviewed by Thibaud et al. [15]. 


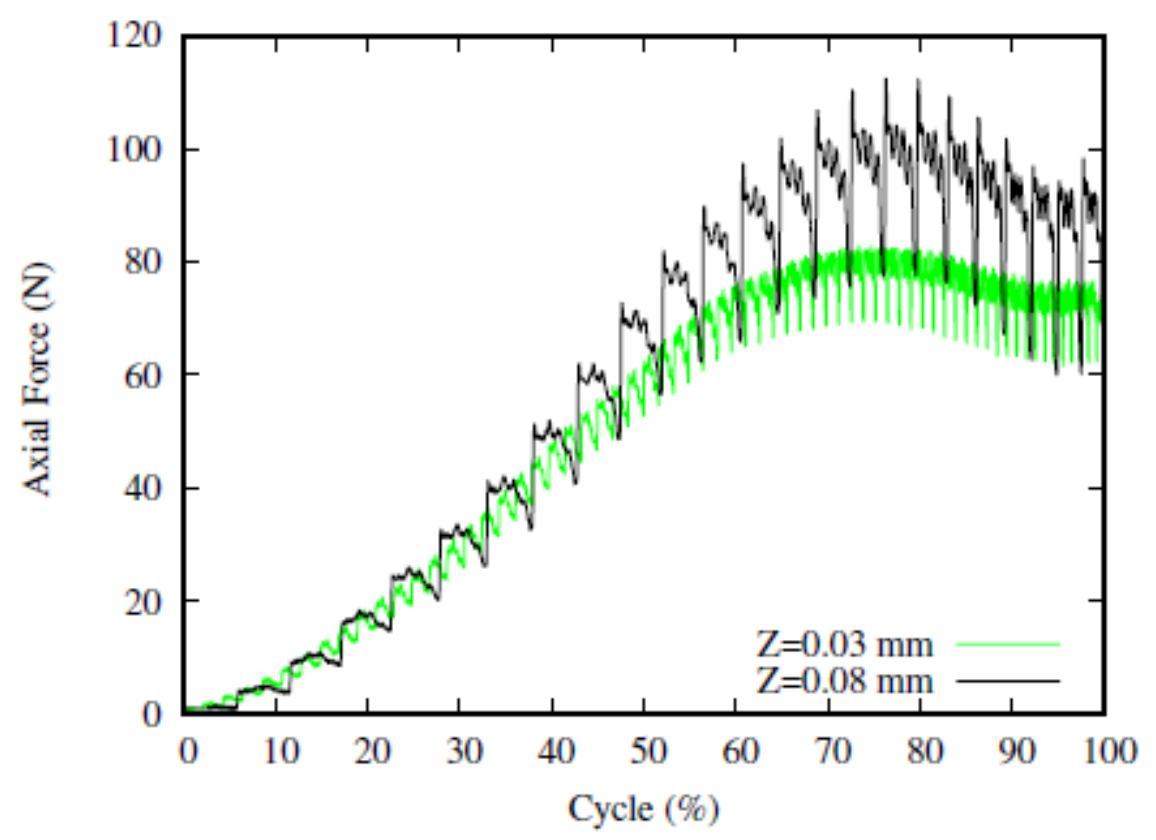

(a)

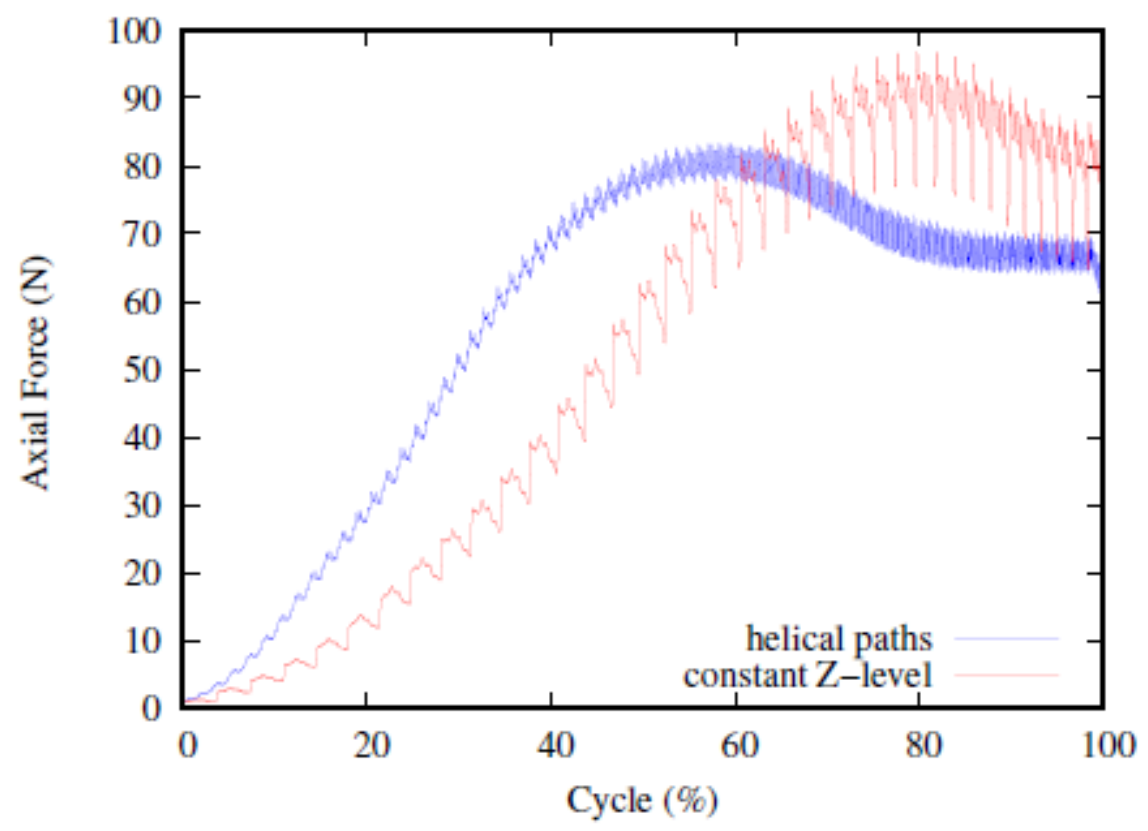

(b)

Figure 4. (a) Comparison of axial force for two cycles of $\mu$ SPIF for two constant Z-level. (b) Comparison of helical and constant Z-level paths. 


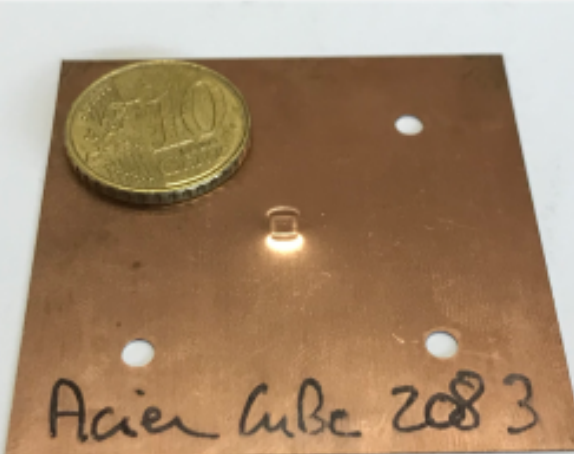

(a)

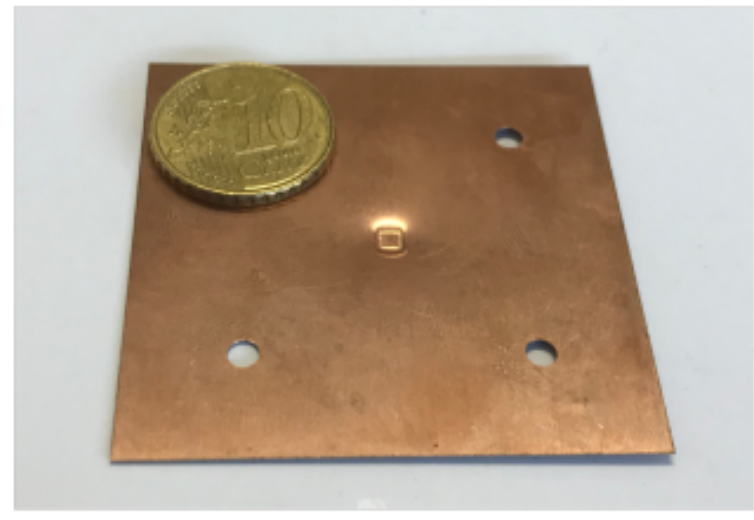

(b)

Figure 5. Geometries of the pyramid after single point incremental forming with the constant Z-level strategy: (a) above side, (b) below side.

Dimensions of the formed pyramid are presented in Fig. 6 and detailed on Table 5.
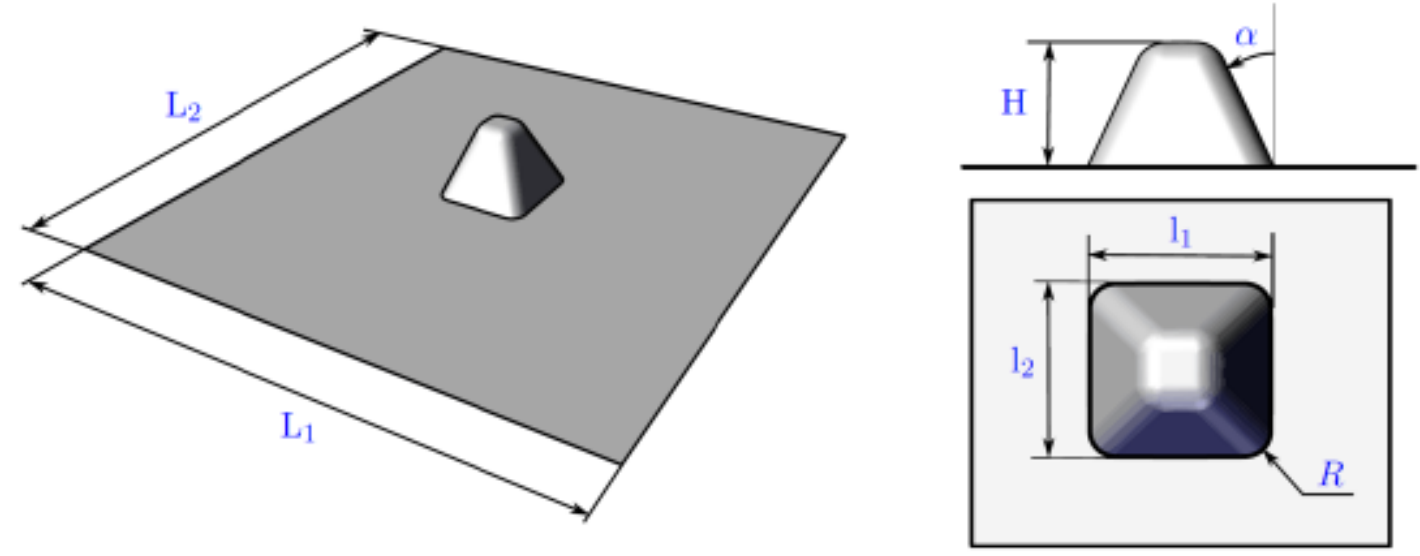

Figure 6. Dimensions of the squared-based pyramid

Table 5. Dimensions of the squared-based pyramid.

\begin{tabular}{ccccccc}
\hline $\mathrm{L}_{1}(\mathrm{~mm})$ & $\mathrm{L}_{2}(\mathrm{~mm})$ & $\mathrm{l}_{1}(\mathrm{~mm})$ & $\mathrm{l}_{2}(\mathrm{~mm})$ & $\mathrm{H}(\mathrm{mm})$ & $\mathrm{R}(\mathrm{mm})$ & $\left.\alpha()^{\circ}\right)$ \\
\hline 50 & 50 & 3 & 3 & 0.8 & 0.5 & 30 \\
\hline
\end{tabular}

\subsection{Numerical simulation of $\mu S P I F$}

A numerical simulation of $\mu$ SPIF is performed in order to compare experimental and numerical forming forces in z-direction with finite element code Abaqus Standard [16]. The constitutive model of the non-associated flow plasticity is introduced as a User Material Subroutine. The elements used are S4R shell elements with 4 nodes with reduced 
integration.

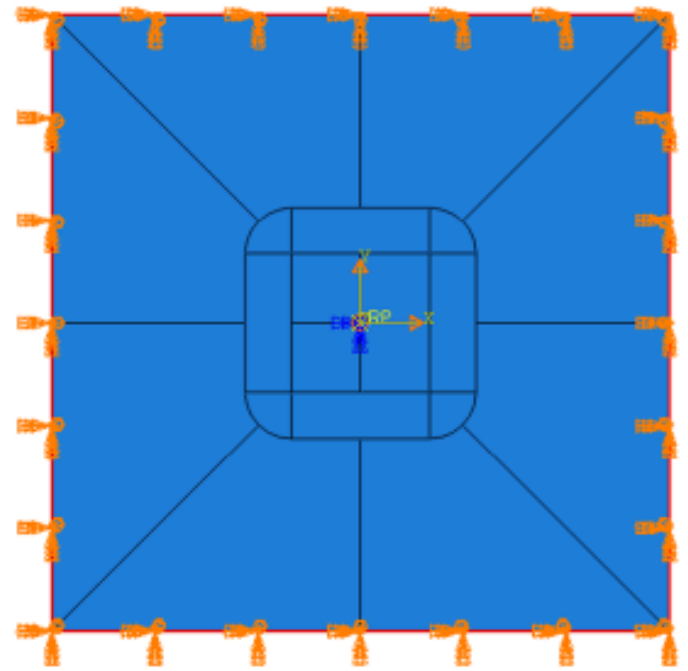

(a) BC.1

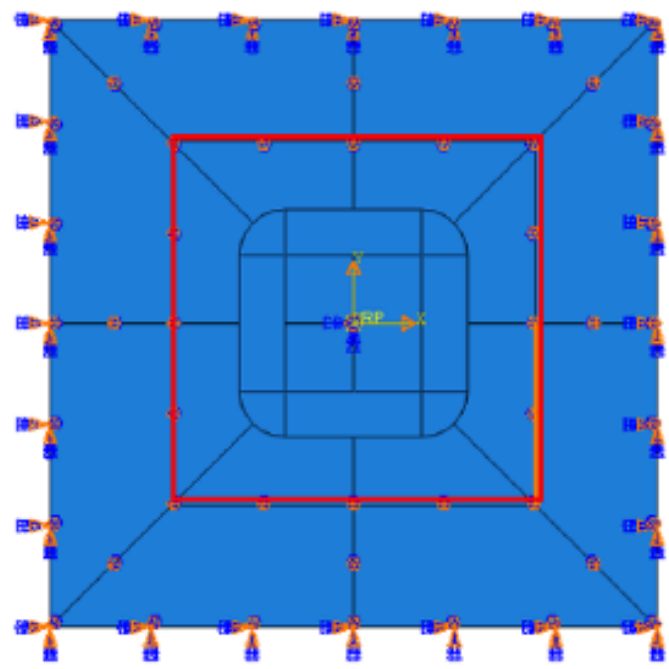

(c) BC.3

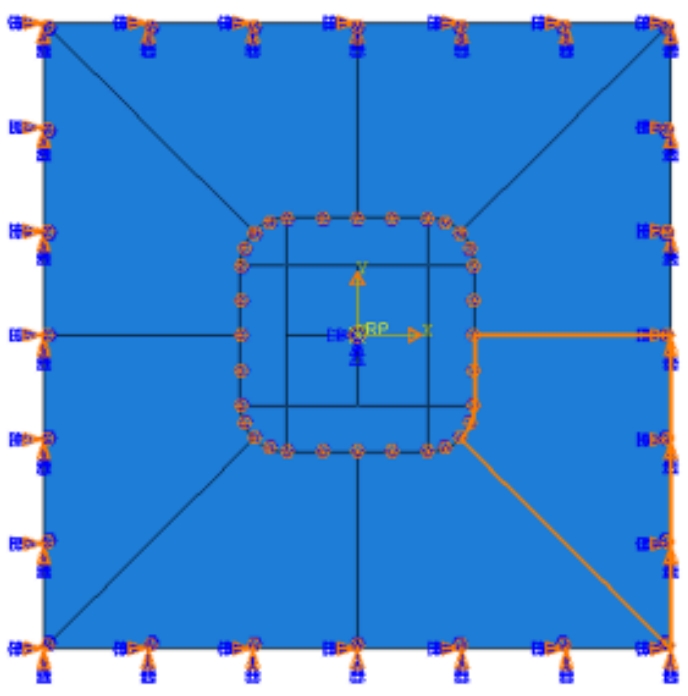

(b) $\mathrm{BC} .2$

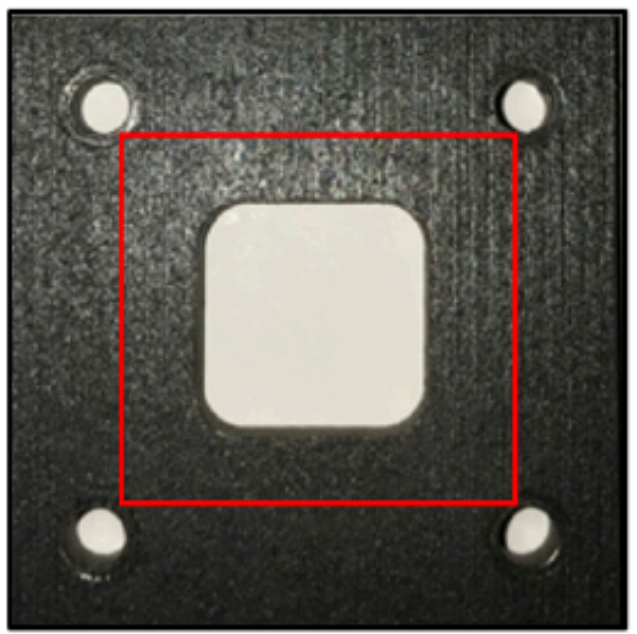

(d) $\mathrm{BC} .3$

Figure 7. Different configurations of boundary conditions of the blank for the simulation of $\mu$ SPIF. The red line represents the location of the effective boundary conditions.

Different boundary conditions are tested according to Fig 7:

- BC.1 the outline of the blank is embedded (Fig 7.a)

- BC.2. the movements of the nodes are blocked along the $\mathrm{Z}$ axis from the outline of the blank to the free inner edge (Fig 7.b)

- BC3. the movements of the nodes are blocked along the $\mathrm{Z}$ axis up to the experimental location of the screws (Fig 7.c, Fig 7.d) 


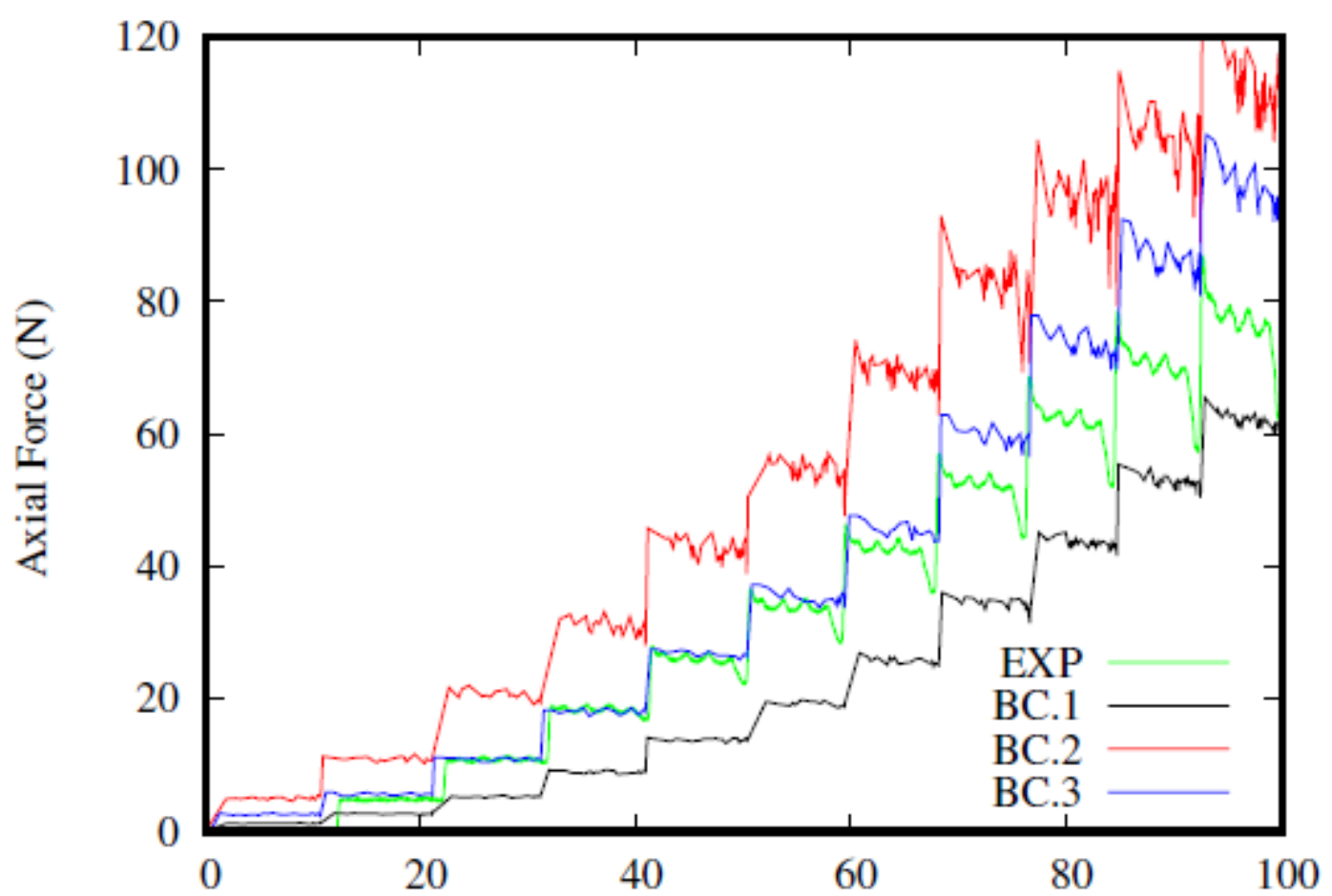

Figure 8. Comparison of axial force for simulation on $\mu$ SPIF with different configurations of boundary conditions

A whole cycle of 11 passes is simulated in Fig.8 in order to reduce computation time, which corresponds to $42 \%$ of the real cycle to build the complete pyramid. It is observed for the BC.1, when only the outline of the blank is embedded, that the axial force is lower that the experimental one because the blank is not supported enough compared to the experimental conditions. Concerning the BC.2, the axial force is higher than the real one if the blank is over blocked. It is with the BC.3, the numerical results are closer to the experimental force which corresponds to the blank blocked until the experimental location of the screws.

In the Fig.9, a comparison between experimental results and simulations is shown. Overall a good match is found. For the first pass the simulated force is greater than the experimental force. After this first pass the two curves are superimposed. Then, after a certain number of passes, the gap between experimental and numerical results increases. It is observed that the more the test progresses the more the deformation increases and the two simulated curves begin to separate. In SPIF, there is a loading and unloading of the material area under the punch, which creates a loading-unloading strain path, which is hardly taken into account in our model since the hardening is only isotropic. The improvement of the results will be achieved by taking into account in the model a kinetic contribution of the hardening. This work is currently in progress. 


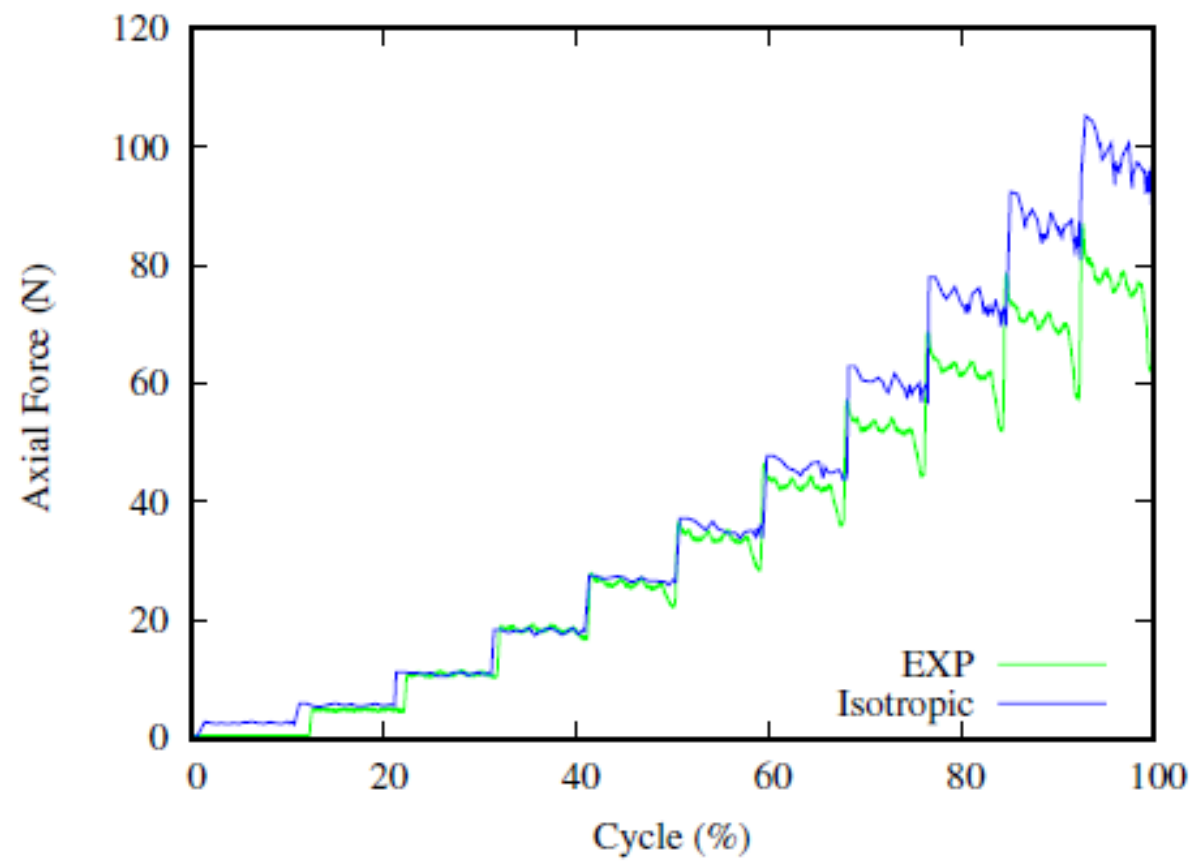

Figure 9. Comparison of the axial force between experimental and numerical curves for simulation of $\mu$ SPIF

In Fig 10. is a simulation of the micro-forming at the end of the process is presented in terms of the effective plastic strain. Values are defined to be equivalent to Hill48 criterion A maximum value of approximately 15\% is reached.
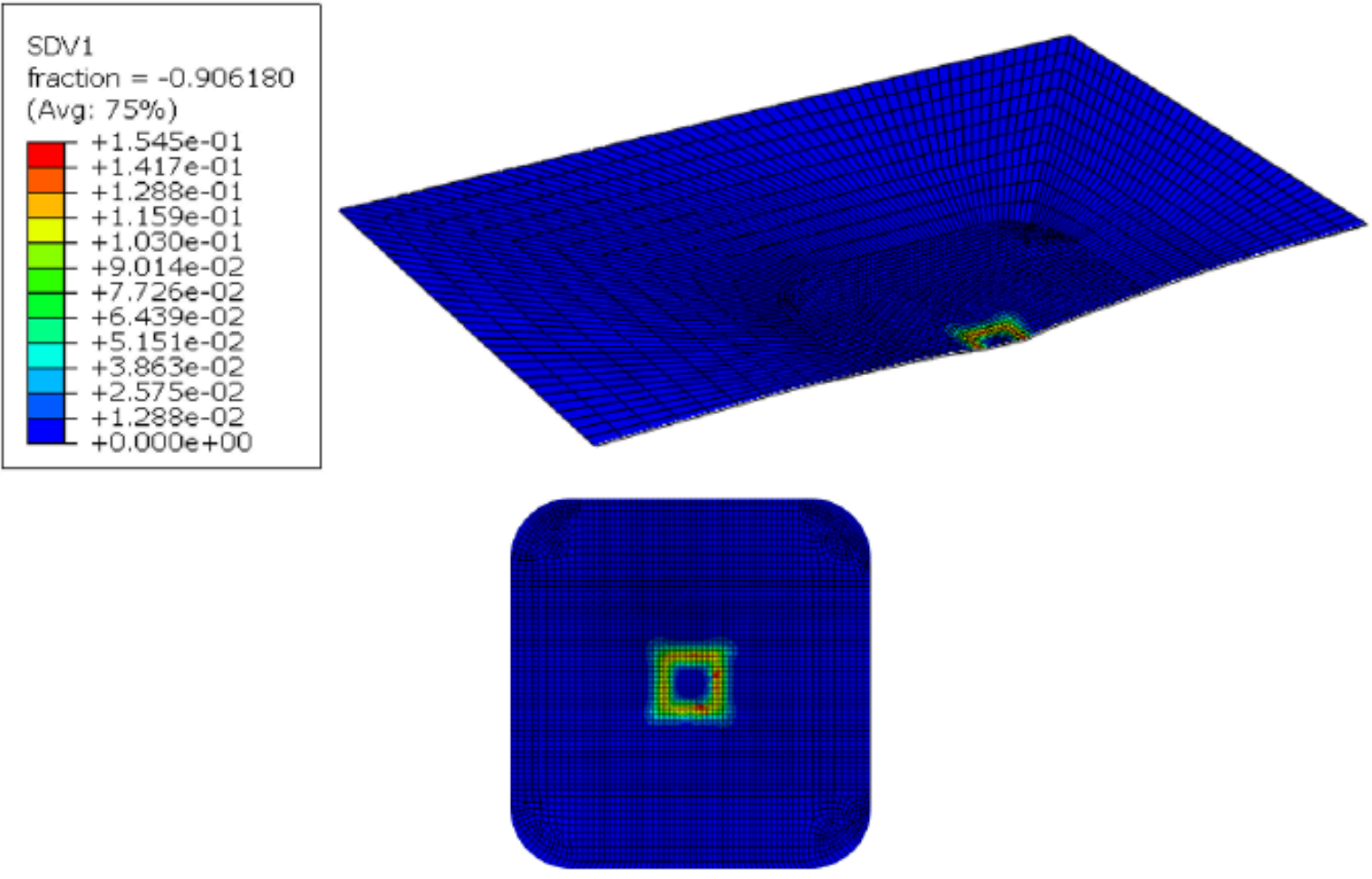
Figure 10. Effective plastic strain at the end of the $\mu$ SPIF simulation

The variety of strain or stress states is also an important factor for an accurate calibration of a constitutive model, especially when a complex yield criterion has to be calibrated. Therefore, the plot of the strain in the principal axes (in-plane) is presented in Fig.11. $\varepsilon_{1}$ and $\varepsilon_{2}$ represent the major and minor strains.

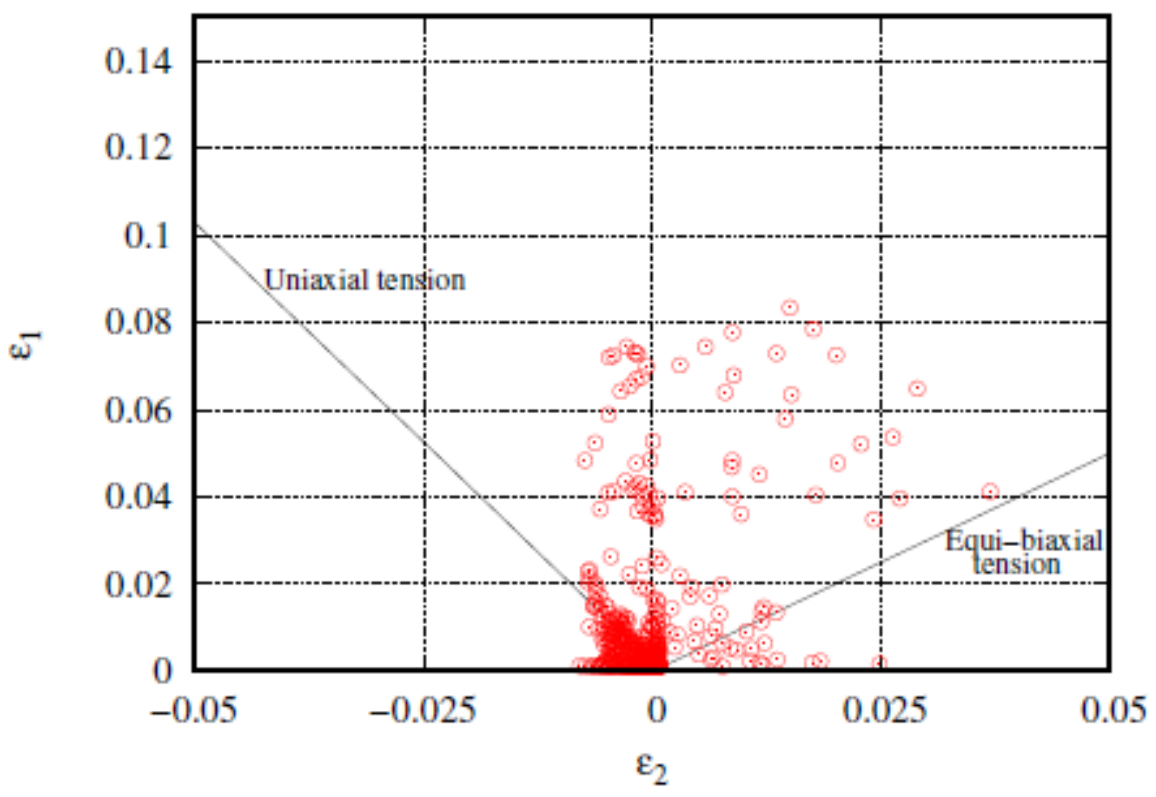

Figure 11. Plot of the principal strain fields during the $\mu$ SPIF simulation

It should be noted in Fig. 11 that there is essentially plane tension. It confirms the use of a non-associated plasticity model to describe this particular state which has difficulty to be predict with associated plasticity models.

Fig.12 presents the shell thickness of the deformed blank after the 11 passes. The thickness is reduced on the edges because of the repetitive passage of the tool to make the different increments of strain. The section thickness of finitestrain shell elements changes as a function of the membrane strain based on the effective section Poisson's ratio $v$.

In plane stress $\sigma_{33}=0$; linear elasticity gives Eq. 11

$$
\varepsilon_{33}=-\frac{v}{1-v}\left(\varepsilon_{11}+\varepsilon_{22}\right)
$$

Treating these as logarithmic strains in Eq. 12 , where $l_{1}{ }^{0}, l_{2}{ }^{0}$ are the initial length and $l_{1}, l_{1}$ the current length.

$$
\ln \left(\frac{t}{t_{0}}\right)=-\frac{v}{1-v}\left(\ln \left(\frac{l_{1}}{l_{1}^{0}}\right)+\ln \left(\frac{l_{2}}{l_{2}^{0}}\right)\right)=-\frac{v}{1-v} \ln \left(\frac{A}{A^{0}}\right)
$$

Where A is the arear on the shell's reference surface. This nonlinear analogy with linear elasticity leads to the thickness change relationship Eq. 13: 
Simulation of the micro Single Point Incremental forming process of very thin sheets

$\frac{t}{t_{0}}=\left(\frac{A}{A_{0}}\right)^{\frac{v}{1-v}}$

$t_{0}$ and $t$ are respectively the initial shell thickness and the current thickness.

In the case of plasticity, $v=0.5$.

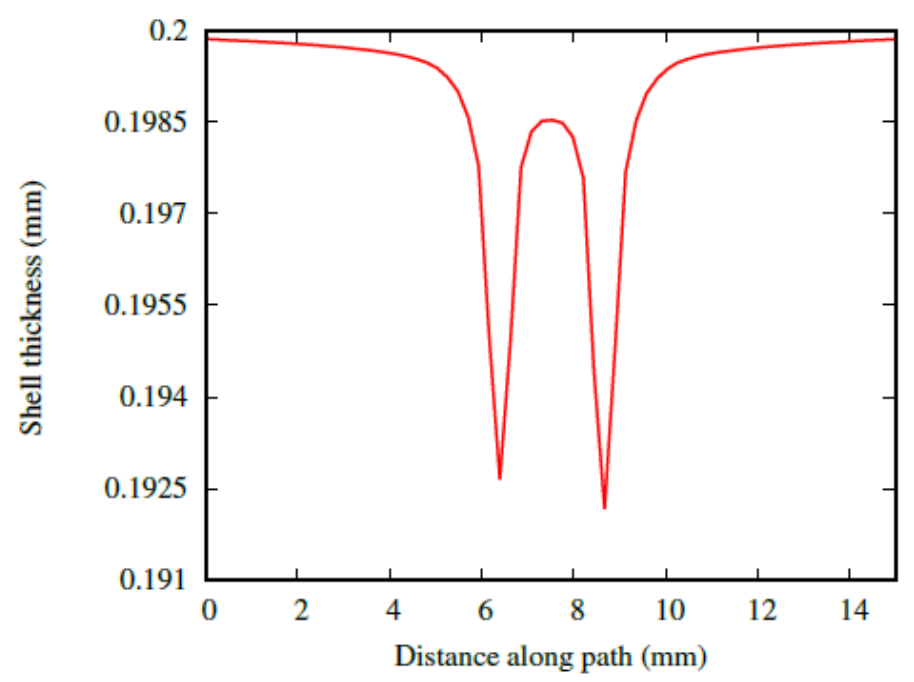

(a)

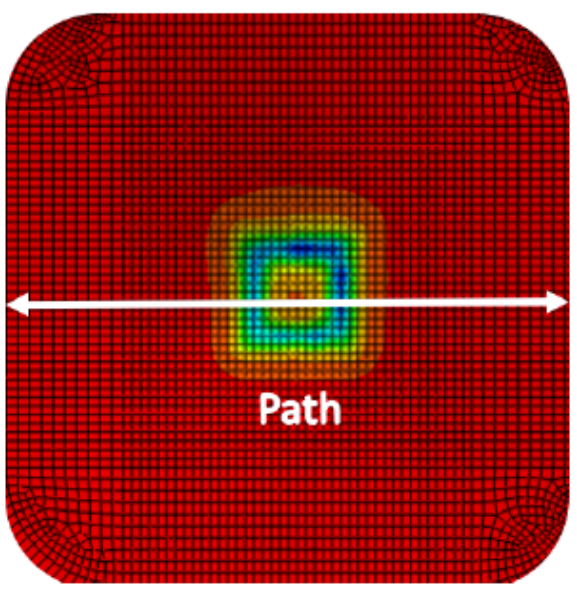

(b)

Figure 12. Shell thickness of the deformed blank (a) at the end of the $\mu$ SPIF simulation along a path (b)

Experimental measurements using a tomograph are in progress to compare experimental and numerical thickness profiles of the formed pyramid.

\section{Conclusion}

This work is dedicated to the simulation of a micro Single Incremental forming process with plastic parameters identified from tensile and shear tests. An elastic-plastic model which combines a Hill's 1948 anisotropic criterion and plastic potential using a non-associated flow rule is retained. Good results are obtained with plastic parameters identified with the classical method. However, other experimental tests such as reversed shear tests will be carried out in the aim to studied other phenomena such as kinematic hardening and to improved our model in order to have results closer to the experimental.

\section{Acknowledgements}

This work has been supported by the EIPHI Graduate school (contract "ANR-17-EURE-0002") and by the Brittany region.

\section{Bibliography}

[1] E. Hagan, J.A. Jeswiet. A review of conventional and modern single-point sheet metal forming methods. Proc Inst 
Mech Eng, Part B : J Eng Manuf 2003;217 :213- 25

[2] N. Powell, C. Andrew. Incremental forming of flanged sheet metal components without dedicated dies. IMechE, PartB : J Eng Manuf 1992;206:41-7

[3] NJ. Jeswiet, E. Hagan. A review of conventional and modern single-point sheet metal forming methods. Eng Manuf $2003: 213-25$

[4] G. Ambrogio, I. Costantino, L. De Napoli, L. Filice, L. Fratini, M. Muzzupappa. Influence of some relevant parameters on the dimensional accuracy in incremental forming : a numerical and experimental investigation. J Mater Process Technol 2004;153-154:501-7

[5] A. Petek, K. Kuzman, J. Kopac. Deformations and forces analysis of single point incremental sheet metal forming. Arc Mater Sci Eng 2009;35:107-16 5 (1989) 51- 66

[6] S. Thuillet, P-Y. Manach, F. Richard, S. Thibaud. Identification de modèles de comportement pour le micro-formage de composants miniatures. 24ème Congrès Français de Mécanique Brest, 26 au 30 août 2019

[7] H. Choia, J. W. Yoon; A Stress integration-based on finite difference method and its application for anisotropic plasticity and distortional hardening under associated and non-associated flow rules. Comput. Methods Appl. Mech. Engrg. 345 (2019) 123-160

[8] F. Barlat, J.C. Brem, J.W. Yoon, K. Chung, R.E. Dick, D.J. Lege, F. Pourboghrat, S.H. Choi, E. Chu, Plane stress yield function for aluminum alloy sheets-part 1 : theory, International Journal of Plasticity, 19 (2003) 1297-1319

[9] R. Hill, A theory of the yielding and plastic flow of anisotropic metals, Proceedings of the Royal Society of London. Series A. Mathematical and Physical Sciences, 193 (1948) 281-297

[10] M. Safaei, W. De Waele, S.L. Zang, Evaluation of associated and non-associeted flow metal plasticity; Application for DC06 deep drawing steel, Key Engineering Materials, 504-506 (2012) 661-666

[11] R.P.R. Cardoso, O.B. Adetoro, A generalisation of the Hill's quadratic yield function for planar plastic anisotropy to consider loading direction, International Journal of Mechanical Sciences, 128-129 (2017) 253-268

[12] F. Richard, MIC2M : Modélisation et Identification du Comportement Mécanique des Matériaux, http ://mic2m.univfcomte.fr 1999

[13] G. Hapsari, F. Richard, R. Ben Hmida, P. Malécot, S. Thibaud. Instrumented Incremental SheetTesting for material behavior extraction under very large strain : Information richness of continuous force measurement. Material \& Design 140 (2018) 317-331

[14] R. Ben Hmida, S. Thibaud, A. Gilbin, F. Richard. Influence of the initial grain size in single point incremental forming process for thin sheets metal and microparts : Experimental investigations Material \& Design 45 (2013) 155-165

[15] S. Thibaud, R. Ben Hmida, F. Richard, P. Malécot. A fully parametric toolbox for the simulation of single point incremental sheet forming process : Numerical feasibility and experimental validation Simulation Modelling Practice and Theory 29, no 0 (décembre 2012) : 32-43

[16] Dassault Systèmes, Simulia, Abaqus 6.6 User Manual, Providence, RI, USA. 2013 
Simulation of the micro Single Point Incremental forming process of very thin sheets

PDF automatically generated on 2021-05-19 14:59:08

Article url: https://popups.uliege.be/esaform21/index.php?id=2715

published by ULiège Library in Open Access under the terms and conditions of the CC-BY License

(https://creativecommons.org/licenses/by/4.0) 